Article

\title{
Seasonal Influenza Vaccination and Recommendation: The Difference between General Practitioners and Public Health Workers in China
}

\author{
Hongguo Rong ${ }^{1, \dagger}$, Xiaozhen Lai ${ }^{2,+}$, Xiaochen Ma ${ }^{1}$, Zhiyuan Hou ${ }^{3}$, Shunping Li ${ }^{4,5} \mathbb{D}$, Rize Jing ${ }^{2}{ }^{\mathbb{D}}$, \\ Haijun Zhang ${ }^{2}$, Zhibin Peng ${ }^{6}$, Luzhao Feng ${ }^{6, *}$ (1) and Hai Fang $1,7,8, *$ \\ 1 China Center for Health Development Studies, Peking University, Beijing 100083, China; \\ hgrong@hsc.pku.edu.cn (H.R.); xma@hsc.pku.edu.cn (X.M.) \\ 2 School of Public Health, Peking University, Beijing 100083, China; laixiaozhen@pku.edu.cn (X.L.); \\ rzjing2015@hsc.pku.edu.cn (R.J.); zhanghj966@bjmu.edu.cn (H.Z.) \\ 3 School of Public Health, Fudan University, Shanghai 200032, China; zyhou@fudan.edu.cn \\ 4 School of Health Care Management, Cheeloo College of Medicine, Shandong University, Jinan 250012, China; \\ lishunping@sdu.edu.cn \\ 5 NHC Key Laboratory of Health Economics and Policy Research, Shandong University, Jinan 250012, China \\ 6 Division of Infectious Diseases, Chinese Center for Disease Control and Prevention, Beijing 102206, China; \\ pengzb@chinacdc.cn \\ 7 Peking University Health Science Center-Chinese Center for Disease Control and Prevention Joint Center for \\ Vaccine Economics, Beijing 100083, China \\ 8 Center for Infectious Disease Research and Policy, Peking University Institute for Global Health, \\ Beijing 100083, China \\ * Correspondence: fenglz@chinacdc.cn (L.F.); hfang@hsc.pku.edu.cn (H.F.); Tel.: +86-10-5890-0541 (L.F.); \\ +86-10-8280-5702 (H.F.) \\ + These authors have contributed equally to this work.
}

Received: 11 May 2020; Accepted: 28 May 2020; Published: 31 May 2020

\begin{abstract}
Seasonal influenza vaccination for healthcare workers (HCWs) is critical to the protection of HCWs and their patients. This study examined whether the separation of public health workers and general practitioners could affect the influenza vaccine uptake and recommendation behaviors among HCWs in China. A survey was conducted from August to October 2019, and HCWs from 10 provinces in China were recruited. A self-administered and anonymous questionnaire was used to assess HCWs' demographic information, knowledge, and attitudes toward influenza vaccination, as well as vaccine uptake and recommendation behaviors. The primary outcome was HCWs' vaccination and recommendation status of seasonal influenza vaccine. Multivariate logistic regression models were used to identify the influence factors of influenza vaccine uptake and recommendation among HCWs. Of the 1159 HCWs in this study, 25.3\% were vaccinated against influenza in the previous season. "No need to get vaccinated" was the primary reason for both unvaccinated public health workers and general practitioners. Multivariate logistic regression showed that public health workers were more likely to get vaccinated against influenza $(\mathrm{OR}=2.20,95 \% \mathrm{CI} 1.59-3.05)$ and recommend influenza vaccination to children $(\mathrm{OR}=2.10,95 \% \mathrm{CI} 1.57-2.80)$ and the elderly $(\mathrm{OR}=1.69,95 \% \mathrm{CI} 1.26-2.25)$ than general practitioners. Besides, the knowledge and perceived risk of influenza can give rise to HCWs' vaccination and recommendation behaviors, and HCWs who got vaccinated in the past year were more likely to recommend it to children and the elderly in their work. The influenza vaccine coverage and recommendation among HCWs are still relatively low in China, especially for general practitioners. Further efforts are needed to improve the knowledge and attitudes toward influenza and influenza
\end{abstract}


vaccination among HCWs, and coherent training on immunization for both public health workers and general practitioners might be effective in the face of separated public health and clinical services in China.

Keywords: healthcare workers; influenza; vaccination; public health workers; general practitioners

\section{Introduction}

The World Health Organization (WHO) estimated that seasonal influenza may affect $5 \%$ to $15 \%$ of the world's population each year, causing as many as 3-5 million severe cases and 290,000-650,000 deaths [1]. Accordingly, influenza places a huge burden on healthcare and social economy in most countries, including China [2]. At present, annual vaccination is the best way to prevent influenza infection [3].

Compared with the general population, healthcare workers (HCWs) are at higher risk of exposure to influenza virus, bringing potential threats for the occupational health of HCWs [4]. Meanwhile, HCWs may therefore represent an important vector for transmission to susceptible patients, including those at high risk for serious outcomes [5]. The technical guidance for influenza vaccination in China (2019-2020) clearly pointed out that HCWs are the priority population for influenza vaccination, together with children (aged between 6 months to 59 months), the elderly (aged 60 years old or above), patients with chronic diseases, family members and caregivers of infants under six months of age, and pregnant women [6]. Nevertheless, the uptake rate of influenza vaccine among HCWs in China has been reported to remain low as $13.5 \%$ in 2015 [7], much lower than that in the United States (78.6\%) [8], the United Kingdom (50.4\%) [9], and Spain (50.7\%) [10]. Provincial influenza vaccination uptake rates differed widely in China partly due to the differential subsidy policies across regions [11]. In 2018, the National Health Committee in China proposed that healthcare facilities should provide influenza vaccination for medical staff for free [12]. This is the first national-wide policy initiative to vaccinate medical practitioners, but it has not been fully implemented across the country. Additionally, HCWs are the major information source about influenza and influenza vaccine for high-risk patients, and the attitudes and beliefs of HCWs can affect the vaccination behaviors of patients, especially children and the elderly $[13,14]$. Therefore, HCWs play an important role in vaccine promotion, and the vaccine recommendation from vaccinated HCWs to patients had profound influence on improving public health. Previous studies have shown than nearly $40-60 \%$ of HCWs in China were not willing to recommend the seasonal influenza vaccine to their patients, which is a large barrier to further improve the vaccine uptake among priority groups $[15,16]$.

Public health workers and general practitioners have direct contact with patients, and their recommendations are important for patients' immunization decisions [17]. However, the medical system and public health system have developed independently in terms of both talent cultivation and staff management in China [18]. Therefore, a long-recognized deficiency of clinical physicians was insufficient education and training on public health [19]. The separation between the two systems also lies in the reimbursement policies, according to which a large proportion of preventive healthcare services, such as influenza vaccination, cannot be reimbursed, while treatment services are usually covered [20]. The lack of effective coordination between the two systems has blocked the integration of medical resources and the share of specialized medical knowledge, which is not conducive to the prevention and treatment of diseases.

In order to increase the coverage and recommendation of influenza vaccination among HCWs, this study used a nationally representative sample to estimate the behaviors of different types of HCWs towards influenza vaccine, aiming to examine whether the separation of public health workers and general practitioners has influence on the seasonal influenza vaccine uptake and recommendation in China. 


\section{Methods}

\subsection{Study Population}

In August to October 2019, a total of 148 community immunization centers from 10 provinces in China were approached to participate in the national survey on influenza vaccination (Strategies of Influenza Vaccination in China study, NCT04038333). In the selected immunization centers, two types of HCWs who were on duty that day were recruited, including public health workers (both doctors and nurses) responsible for vaccination and randomly selected general practitioners. After excluding the samples with missing key demographic variables or outcome variables $(n=131)$, a total of 1159 HCWs, including 627 public health workers and 532 general practitioners, were finally included in the study. This study was approved by Peking University Institutional Review Board (IRB00001052-19076).

The survey used a multi-stage stratified sampling method. First, 10 provinces/municipalities/autonomous regions were selected based on the Division of Central and Local Financial Governance and Expenditure Responsibilities in the Healthcare Sector released by the General Office of the State Council in 2018, which divided 31 provinces/municipalities/autonomous regions in mainland China into five layers [20]. After considering the location, socioeconomic development, and accessibility, 3, $3,1,1$, and 2 provinces/municipalities/autonomous regions were chosen from each layer, as showed in Figure 1. Second, in each province/municipality/autonomous region, a capital city (or a well-developed district in municipalities) and a non-capital city (or a less-developed district) were selected. Third, two subdistricts/counties were chosen in each city or district. Fourth, in each subdistrict/county, three or more immunization centers (settled in community health centers or township clinics), and the corresponding neighborhood committees were approached to participate.

\subsection{Measures}

A self-administered and anonymous questionnaire was adopted and modified from the Respiratory Illness and Health Care Worker Study designed by the United States Centers for Disease Control and Prevention [21]. According to the actual conditions in China, we mainly used questions on reasons for not being vaccinated, knowledge of the six target groups for influenza vaccination, and vaccine recommendation behaviors in the present study. The questionnaire can be divided into four parts-(1) demographics; (2) vaccination and recommendation behaviors; (3) knowledge of and attitudes about influenza; and (4) knowledge of and attitudes towards influenza vaccine. Participants chose the extent to which they agree or disagree with scale items based on a five-point Likert scale. In addition, unvaccinated HCWs were asked to answer seven additional questions about the reasons for not being vaccinated.

\subsection{Statistical Analysis}

The chi-square test and Mann-Whitney test were used to assess possible differences in socio-demographics, knowledge of and attitudes towards influenza and influenza vaccination among HCWs. Multivariate logistic regression analysis was adopted to predict the influencing factors of vaccination and recommendation behaviors of HCWs. Results were showed as odds ratios (OR) and 95\% confidence intervals (CI). A two-sided $p$-value below 0.05 was considered statistically significant. All data were analyzed using STATA, version 13.0 (Stata Corp, College Station, TX, USA). 


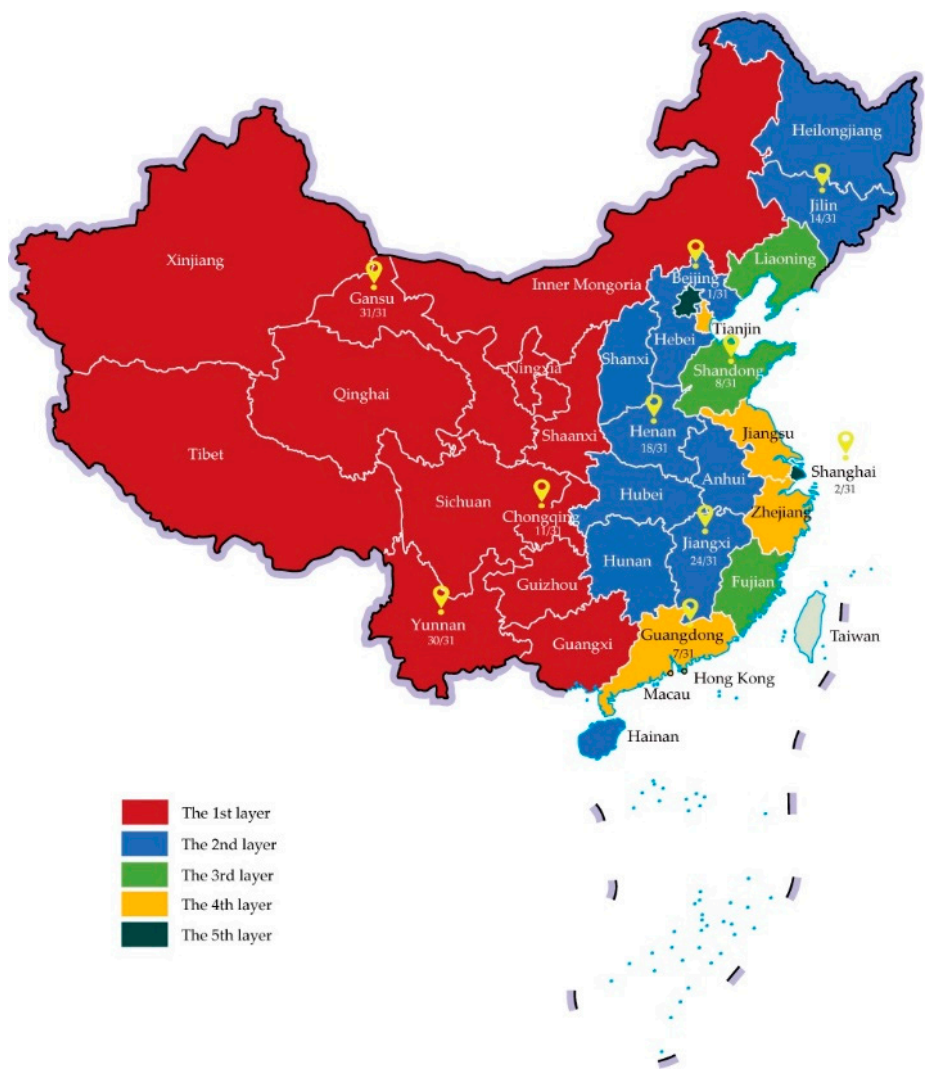

Figure 1. Ten provinces/municipalities/autonomous regions selected in China.

\section{Results}

\subsection{Study Sample Characteristics}

Table 1 showed the general characteristics, knowledge, and attitudes about influenza and influenza vaccine among HCWs. The respondents were mainly female (78.4\%), and the mean age was 36.4 years old. The overall influenza vaccination rate was $25.3 \%$, and the difference in vaccine uptake between public health doctors $(30.5 \%)$ and general practitioners $(19.2 \%)$ was significant $(p<0.01)$. There were significant differences between two kinds of HCWs in terms of age, gender, education level, monthly income, recommendation behaviors for children/the elderly, self-reported severity of influenza, and knowledge on the incubation period for influenza vaccination (all $p<0.01$ ). Particularly, $62.4 \%$ of public health doctors and $49.1 \%$ of general practitioners recommended influenza vaccination to children, and $68.1 \%$ of public health doctors and $54.7 \%$ of general practitioners recommended it to the elderly.

\subsection{Reasons for Not Being Vaccinated}

Of the $1159 \mathrm{HCWs}$ in this study, 866 (74.7\%) participants were unvaccinated. We further investigated the reasons why they were not vaccinated, including "high vaccine price," "allergic contraindications," "worry about adverse reactions," "low vaccine efficacy," "vaccine shortage in local areas," "no need to get vaccinated," and "inadequate vaccine accessibility" (Table 2). Among the unvaccinated HCWs, "no need to get vaccinated" was the primary reason for both public health workers (205/436) and general practitioners (282/430). High vaccine price was another important reason, as doctors needed to pay for influenza vaccination out of pocket. 
Table 1. Characteristics of surveyed healthcare workers in immunization centers.

\begin{tabular}{|c|c|c|c|}
\hline & Public Health Workers, $n(\%)$ & General Practitioners, $n(\%)$ & $p$-Value \\
\hline Outcomes & & & \\
\hline Vaccination history in the previous season & & & $<0.01^{*}$ \\
\hline Vaccinated & $191(30.5)$ & $102(19.2)$ & \\
\hline Unvaccinated & $436(69.5)$ & $430(80.8)$ & \\
\hline Recommended influenza vaccination to children & & & $<0.01 *$ \\
\hline Yes & $391(62.4)$ & $261(49.1)$ & \\
\hline No & $236(37.6)$ & $271(50.9)$ & \\
\hline Recommended influenza vaccination to elderly & & & $<0.01 *$ \\
\hline Yes & $427(68.1)$ & $291(54.7)$ & \\
\hline No & $200(31.9)$ & $241(45.3)$ & \\
\hline Knowledge and perception of influenza vaccination & & & \\
\hline Self-reported high severity of influenza & & & 0.01 \\
\hline Yes & $320(51.0)$ & $233(43.8)$ & \\
\hline No & $307(49.0)$ & $299(56.2)$ & \\
\hline Self-reported high possibility of catching influenza & & & 0.95 \\
\hline Yes & $172(27.4)$ & $145(27.3)$ & \\
\hline No & 455 (72.6) & $387(72.7)$ & \\
\hline $\begin{array}{l}\text { Knowledge-The best timing to vaccinate is } 1-2 \\
\text { months before the influenza epidemic peak }\end{array}$ & & & 0.18 \\
\hline Yes & $491(78.3)$ & $399(75.0)$ & \\
\hline No & $136(21.7)$ & $133(25.0)$ & \\
\hline $\begin{array}{l}\text { Knowledge-The incubation period of influenza is } \\
1-4 \text { days }\end{array}$ & & & $<0.01 *$ \\
\hline Yes & $293(46.7)$ & $292(54.9)$ & \\
\hline No & $334(53.3)$ & $240(45.1)$ & \\
\hline $\begin{array}{l}\text { Knowledge-Influenza virus in droplets can live for } \\
\qquad 30 \text { minutes in the air }\end{array}$ & & & 0.50 \\
\hline Yes & $169(27.0)$ & $134(25.2)$ & \\
\hline No & $458(73.0)$ & $398(74.8)$ & \\
\hline General characteristics & & & \\
\hline Age (years) & & & $<0.01 *$ \\
\hline$<30$ & $200(31.9)$ & $103(19.4)$ & \\
\hline 30-39 & $229(36.5)$ & $205(38.5)$ & \\
\hline $40-49$ & $164(26.2)$ & $160(30.1)$ & \\
\hline$\geq 50$ & $34(5.4)$ & $64(12.0)$ & \\
\hline Gender & & & $<0.01 *$ \\
\hline Female & $566(90.3)$ & $343(64.5)$ & \\
\hline Male & $61(9.7)$ & $189(35.5)$ & \\
\hline Education level & & & $<0.01 *$ \\
\hline High school and below & $82(13.1)$ & $69(13.0)$ & \\
\hline Junior college & $284(45.3)$ & $166(31.2)$ & \\
\hline Bachelor and above & 261 (41.6) & $297(55.8)$ & \\
\hline Monthly income (CNY) & & & $<0.01 *$ \\
\hline$\leq 3000$ & $293(46.7)$ & $147(27.6)$ & \\
\hline $3001-4000$ & $114(18.2)$ & $112(21.1)$ & \\
\hline $4001-5000$ & $97(15.5)$ & $121(22.7)$ & \\
\hline$>5000$ & $123(19.6)$ & $152(28.6)$ & \\
\hline Having children under 6 years & & & 0.96 \\
\hline Yes & $236(37.6)$ & $201(37.8)$ & \\
\hline No & $391(62.4)$ & 331 (62.2) & \\
\hline Self-reported good health status & & & 0.10 \\
\hline Yes & $441(70.3)$ & $397(74.6)$ & \\
\hline No & $186(29.7)$ & $135(25.4)$ & \\
\hline Having chronic diseases & & & 0.17 \\
\hline Yes & $46(7.3)$ & $51(9.6)$ & \\
\hline No & $581(92.7)$ & $481(90.4)$ & \\
\hline Place of residence & & & 0.74 \\
\hline Rural & $238(38.0)$ & $207(38.9)$ & \\
\hline Urban & $389(62.0)$ & $325(1.1)$ & \\
\hline
\end{tabular}


Table 2. Reasons for not being vaccinated among healthcare workers (HCWs).

\begin{tabular}{ccccc}
\hline & $\begin{array}{c}\text { Public Health Workers } \\
(\boldsymbol{n}=\mathbf{4 3 6 )}\end{array}$ & \multicolumn{2}{c}{$\begin{array}{c}\text { General Practitioners } \\
(\boldsymbol{n}=\mathbf{4 3 0 )}\end{array}$} \\
\cline { 2 - 5 } & $\boldsymbol{n}$ & $\mathbf{\%}$ & $\boldsymbol{n}$ & $\%$ \\
\hline No need to get vaccinated & 205 & 47.0 & 282 & 65.6 \\
High vaccine price & 54 & 12.4 & 65 & 15.1 \\
Vaccine shortage in local areas & 59 & 13.5 & 29 & 6.7 \\
Worry about adverse reactions & 29 & 6.7 & 42 & 9.8 \\
Allergic contraindications & 34 & 7.8 & 30 & 7.0 \\
Low vaccine efficacy & 22 & 5.0 & 39 & 9.1 \\
Inadequate vaccine & 19 & 4.4 & 28 & 6.5 \\
accessibility & 109 & 25.0 & 80 & 18.6 \\
Other reasons & & & & \\
\hline
\end{tabular}

Note: Reasons for not being vaccinated were not mutually exclusive. The percentage sum of all the reasons were more than $100 \%$, as some HCWs chose more than one reason.

\subsection{HCWs' Knowledge of Target Groups}

Table 3 displayed HCWs' knowledge of the six target groups for influenza vaccination. It was found that $81.2 \%$ general practitioners knew that patients with chronic diseases were one of the priority groups for influenza vaccination, and this proportion was higher than that in public health workers $(74.3 \%, p<0.01)$. Compared with unvaccinated HCWs, there was a higher proportion of vaccinated HCWs who knew that the target groups for influenza vaccination covered children, the elderly, patients with chronic diseases, HCWs, and family members and caregivers of infants under six months.

\subsection{Multivariate Predictors of Vaccination}

As showed in Table 4, in the multivariate logistic regression model adjusted for socio-demographics, the type of HCWs, knowledge of and attitudes toward influenza and influenza vaccination, and previous history of vaccination, we founded that being public health workers (odds ratios [OR] $=2.20,95 \% \mathrm{CI}$ $1.59-3.05, p<0.01)$, knowing that HCWs are among the priority groups (OR $=2.61,95 \%$ CI $1.63-4.16$, $p<0.01$ ), self-reporting high severity of influenza (OR $=1.56,95 \% \mathrm{CI} 1.12-2.17, p<0.01$ ) or high possibility of catching influenza $(\mathrm{OR}=1.92,95 \% \mathrm{CI} 1.36-2.71, p<0.01)$, and knowing the best timing to vaccinate against influenza $(\mathrm{OR}=1.46,95 \% \mathrm{CI} 1.00-2.12, p=0.05)$ were positively related to $\mathrm{HCWs}^{\prime}$ vaccination behaviors.

\subsection{Multivariate Predictors of Recommendation}

In the present study, the recommendation behaviors of HCWs were quantified as whether recommend influenza vaccination to children and the elderly. The first three columns of Table 5 showed the multivariate logistic regression results of recommendation to children. The recommendation behavior was positively associated with vaccination history in the previous season ( $\mathrm{OR}=2.79,95 \%$ CI 1.99-3.93, $p<0.01)$, being public health workers (OR $=2.10,95 \%$ CI 1.57-2.80, $p<0.01)$, knowing that children are among priority groups $(\mathrm{OR}=2.20,95 \% \mathrm{CI} 1.63-2.96, p<0.01)$, and knowing the best timing for influenza vaccination $(\mathrm{OR}=1.43,95 \% \mathrm{CI} 1.05-1.95, p=0.02)$. 
Table 3. HCWs' knowledge of different target groups for influenza vaccination.

\begin{tabular}{|c|c|c|c|c|c|c|}
\hline & \multicolumn{3}{|c|}{ Vaccination Status } & \multicolumn{3}{|c|}{ Type of HCWs } \\
\hline & Vaccinated, $n(\%)$ & Unvaccinated, $n(\%)$ & $p$-Value & $\begin{array}{c}\text { Public Health Workers, } \\
n(\%)\end{array}$ & $\begin{array}{c}\text { General PractitioNers, } \\
n(\%)\end{array}$ & $p$-Value \\
\hline $\begin{array}{l}\text { Knowing HCWs are } \\
\text { among target groups }\end{array}$ & $268(91.5)$ & $615(77.1)$ & $<0.01$ * & $504(80.4)$ & $432(81.2)$ & 0.72 \\
\hline $\begin{array}{l}\text { Knowing children aged } \\
6-59 \text { months are among } \\
\text { target groups }\end{array}$ & $232(79.2)$ & $615(71.0)$ & $<0.01 *$ & $458(73.1)$ & $389(73.1)$ & 0.98 \\
\hline $\begin{array}{c}\text { Knowing the elderly } \geq 60 \\
\text { years are among target } \\
\text { groups }\end{array}$ & $282(96.3)$ & $773(89.3)$ & $<0.01$ * & $576(91.9)$ & $479(90.0)$ & 0.28 \\
\hline $\begin{array}{l}\text { Knowing patients with } \\
\text { chronic diseases are } \\
\text { among target groups }\end{array}$ & $243(82.9)$ & $655(75.6)$ & 0.01 * & $466(74.3)$ & $432(81.2)$ & $<0.01 *$ \\
\hline $\begin{array}{l}\text { Knowing family members } \\
\text { and caregivers of infants } \\
\text { under six months are } \\
\text { among target groups }\end{array}$ & $229(78.2)$ & $581(67.1)$ & $<0.01 *$ & $432(68.9)$ & $378(71.1)$ & 0.43 \\
\hline $\begin{array}{l}\text { Knowing pregnant } \\
\text { women are among target } \\
\text { groups }\end{array}$ & $124(42.3)$ & $340(39.3)$ & 0.36 & $240(38.3)$ & 42.1 & 0.19 \\
\hline
\end{tabular}

Table 4. Influencing factors of vaccine uptake among HCWs (multiple logistic regression).

\begin{tabular}{|c|c|c|}
\hline Title & OR $(95 \%$ CI $)$ & $p$-Value \\
\hline \multicolumn{3}{|l|}{ Type of HCWs } \\
\hline General practitioner & Reference & \\
\hline public health worker & $2.20(1.59-3.05)$ & $<0.01 *$ \\
\hline $\begin{array}{c}\text { Know HCWs are among the priority groups for } \\
\text { vaccination }\end{array}$ & $2.61(1.63-4.16)$ & $<0.01 *$ \\
\hline Self-reported high severity of influenza & $1.56(1.12-2.17)$ & $<0.01$ * \\
\hline $\begin{array}{l}\text { Self-reported high possibility of catching } \\
\text { influenza }\end{array}$ & $1.92(1.36-2.71)$ & $<0.01 *$ \\
\hline $\begin{array}{l}\text { Know the best timing to vaccinate is } 1-2 \\
\text { months before the influenza epidemic peak }\end{array}$ & $1.46(1.00-2.12)$ & 0.05 \\
\hline $\begin{array}{c}\text { Know the incubation period of influenza is } 1-4 \\
\text { days }\end{array}$ & $0.74(0.55-1.00)$ & 0.05 \\
\hline $\begin{array}{c}\text { Know influenza virus in droplets can live for } 30 \\
\text { minutes in the air }\end{array}$ & $0.86(0.61-1.21)$ & 0.38 \\
\hline \multicolumn{3}{|l|}{ Age (years) } \\
\hline$<30$ & Reference & \\
\hline 30-39 & $2.08(1.35-3.20)$ & $<0.01 *$ \\
\hline $40-49$ & $2.72(1.67-4.45)$ & $<0.01 *$ \\
\hline$\geq 50$ & $3.50(1.78-6.91)$ & $<0.01 *$ \\
\hline \multicolumn{3}{|l|}{ Gender } \\
\hline Female & Reference & \\
\hline Male & $0.84(0.56-1.25)$ & 0.38 \\
\hline \multicolumn{3}{|l|}{ Education level } \\
\hline High school and below & Reference & \\
\hline Junior college & $1.24(0.75-2.04)$ & 0.40 \\
\hline Bachelor and above & $1.18(0.69-2.01)$ & 0.56 \\
\hline \multicolumn{3}{|l|}{ Monthly income (CNY) } \\
\hline$\leq 3000$ & Reference & \\
\hline $3001-4000$ & $0.95(0.60-1.49)$ & 0.81 \\
\hline $4001-5000$ & $1.13(0.69-1.85)$ & 0.62 \\
\hline$>5000$ & $1.37(0.77-2.44)$ & 0.28 \\
\hline Having children under 6 years & $1.41(0.99-2.00)$ & 0.06 \\
\hline Self-reported good health status & $1.03(0.74-1.45)$ & 0.85 \\
\hline Having chronic diseases & $1.12(0.65-1.91)$ & 0.69 \\
\hline \multicolumn{3}{|l|}{ Place of residence } \\
\hline Rural & Reference & \\
\hline Urban & $1.01(0.73-1.40)$ & 0.95 \\
\hline
\end{tabular}

Note: The regression was controlled for province. ${ }^{*} p<0.05$. 
Table 5 also showed the results of recommendation to the elderly, indicating that vaccination history in the previous season (OR $=2.80,95 \% \mathrm{CI} 1.96-4.00, p<0.01)$, being public health workers $(\mathrm{OR}=1.69,95 \%$ CI 1.26-2.25, $p<0.01)$, knowing that the elderly are among priority groups (OR $=3.45,95 \% \mathrm{CI} 2.13-5.59$, $p<0.01)$, knowing the best timing for influenza vaccination ( $\mathrm{OR}=1.77,95 \% \mathrm{CI} 1.30-2.42, p<0.01$ ), knowing the incubation period of influenza (OR $=1.47,95 \%$ CI 1.12-1.95, $p<0.01$ ) would significantly increase the possibility to recommend influenza vaccination to the elderly.

Table 5. Influencing factors of HCWs' vaccination recommendation to children or the elderly (multiple logistic regression).

\begin{tabular}{|c|c|c|c|c|}
\hline & \multicolumn{2}{|c|}{ Recommendation to Children } & \multicolumn{2}{|c|}{ Recommendation to the Elderly } \\
\hline & OR $(95 \%$ CI $)$ & $p$-Value & OR $(95 \% \mathrm{CI})$ & $p$-Value \\
\hline $\begin{array}{c}\text { Vaccinated in the previous season } \\
\text { Type of HCWs }\end{array}$ & $2.79(1.99-3.93)$ & $<0.01 *$ & $2.80(1.96-4.00)$ & $<0.01^{*}$ \\
\hline General practitioner & Reference & & Reference & \\
\hline public health worker & $2.10(1.57-2.80)$ & $<0.01 *$ & $1.69(1.26-2.25)$ & $<0.01^{*}$ \\
\hline $\begin{array}{l}\text { Know children (the elderly) are } \\
\text { among the target groups for } \\
\text { vaccination }\end{array}$ & $2.20(1.63-2.96)$ & $<0.01 *$ & $3.45(2.13-5.59)$ & $<0.01^{*}$ \\
\hline $\begin{array}{c}\text { Self-reported high severity of } \\
\text { influenza }\end{array}$ & $1.18(0.88-1.58)$ & 0.26 & $1.22(0.91-1.63)$ & 0.19 \\
\hline $\begin{array}{l}\text { Self-reported high possibility of } \\
\text { catching influenza }\end{array}$ & $1.31(0.94-1.83)$ & 0.12 & $1.24(0.89-1.75)$ & 0.21 \\
\hline $\begin{array}{l}\text { Know the best timing to vaccinate } \\
\text { against influenza is 1-2 months } \\
\text { before the influenza epidemic peak }\end{array}$ & $1.43(1.05-1.95)$ & $0.02 *$ & $1.77(1.30-2.42)$ & $<0.01 *$ \\
\hline $\begin{array}{l}\text { Know the incubation period of } \\
\text { influenza is } 1-4 \text { days }\end{array}$ & $1.21(0.92-1.59)$ & 0.18 & $1.47(1.12-1.95)$ & $<0.01 *$ \\
\hline $\begin{array}{c}\text { Know influenza virus in droplets can } \\
\text { live for } 30 \text { minutes in the air } \\
\text { Age (years) }\end{array}$ & $1.06(0.79-1.43)$ & 0.70 & $1.29(0.95-1.75)$ & 0.10 \\
\hline$<30$ & Reference & & & \\
\hline $30-39$ & $1.08(0.75-1.56)$ & 0.66 & $0.94(0.65-1.35)$ & 0.72 \\
\hline $40-49$ & $1.18(0.77-1.8)$ & 0.46 & $0.95(0.62-1.47)$ & 0.83 \\
\hline$\geq 50$ & $1.44(0.77-2.72)$ & 0.26 & $0.84(0.45-1.57)$ & 0.58 \\
\hline Gender & & & & \\
\hline Female & Reference & & & \\
\hline Male & $1.08(0.76-1.52)$ & 0.68 & $0.69(0.49-0.97)$ & $0.03 *$ \\
\hline Education level & & & & \\
\hline High school and below & Reference & & & \\
\hline Junior college & $0.59(0.38-0.92)$ & $0.02 *$ & $1.01(0.65-1.56)$ & 0.98 \\
\hline Bachelor and above & $0.64(0.4-1.04)$ & 0.07 & $0.75(0.47-1.20)$ & 0.23 \\
\hline Monthly income & & & & \\
\hline$\leq 3000$ & Reference & & & \\
\hline $3001-4000$ & $1.63(1.09-2.43)$ & $0.02 *$ & $1.13(0.76-1.67)$ & 0.56 \\
\hline $4001-5000$ & $1.6(1.02-2.50)$ & $0.04 *$ & $1.7(1.08-2.68)$ & $0.02 *$ \\
\hline$>5000$ & $1.6(0.95-2.71)$ & 0.08 & $1.96(1.15-3.33)$ & $<0.01 *$ \\
\hline Having children under 6 years & $1.1(0.81-1.5)$ & 0.56 & $0.81(0.59-1.11)$ & 0.19 \\
\hline Self-reported good health status & $1.11(0.82-1.52)$ & 0.50 & $1.18(0.86-1.61)$ & 0.31 \\
\hline Having chronic diseases & $1.09(0.64-1.85)$ & 0.76 & $1.5(0.87-2.59)$ & 0.15 \\
\hline Place of residence & & & & \\
\hline Rural & Reference & & & \\
\hline Urban & $0.8(0.6-1.07)$ & 0.12 & $0.96(0.72-1.29)$ & 0.78 \\
\hline
\end{tabular}




\section{Discussion}

To the best of our knowledge, this is the first study using a nationally representative sample to investigate the immunization and recommendation behaviors of influenza vaccine among community-level HCWs in China. This study suggested that the overall coverage rate of influenza vaccine among Chinese HCWs was $25.3 \%$, with public health workers having a higher rate than general practitioners. In addition, the prior vaccination history of HCWs is an important factor affecting their recommendation behaviors.

Despite the strong recommendation for annual influenza vaccination among HCWs made by the WHO and the Chinese Center for Disease Control and Prevention, the uptake rate in practice remains inadequate, which is much lower than that in other countries. Previous studies showed that the knowledge and attitudes of HCWs were positively associated with HCWs' vaccination behaviors, and their misconceptions about influenza and influenza vaccination may reduce their willingness to get vaccinated [22,23]. Only $26.1 \%$ of the HCWs in our study knew that influenza virus in droplets can live for 30 minutes in the air, and only about half of them knew the incubation period of influenza.

The major barrier for both unvaccinated public health workers and general practitioners was "no need to get vaccinated." The multiple logistic regression model showed that being public health worker, knowing that HCWs are among the priority groups, self-reporting higher severity of influenza or higher possibility of catching influenza, and knowing the best timing to vaccinate against influenza came out to be the independent factors affecting the vaccination status of HCWs, in line with a previous study that showed that the attitudes toward influenza vaccination were the strongest predictor of HCWs' intention and actual receipt of influenza vaccination [24]. The present study suggested that both public health workers and general practitioners in China should improve their knowledge of and attitudes toward influenza vaccination. Interventions to promote vaccination should consider both the social norm approach and the individual beliefs of targeted HCWs.

It has been reported that lack of doctors' recommendation was the most common reason for the elderly and children to remain unvaccinated $[25,26]$. Our study suggested that nearly half of the HCWs have not recommended influenza vaccination to the elderly and children. Prior vaccination history, knowing that elderly/children are among the priority groups, and knowledge on influenza and influenza vaccine (such as the incubation period of influenza and the best vaccination time of influenza vaccine) are important influencing factors of HCWs' recommendation behaviors. This is consistent with previous studies which showed that vaccinated HCWs were more likely to recommend influenza vaccine to vulnerable patients $[9,27,28]$, and insufficient or misunderstanding knowledge of influenza vaccine was the reason why primary HCWs rarely recommended influenza vaccine to patients [29]. In this sense, measures taken to expand the vaccine coverage among HCWs and widen their knowledge on influenza vaccination could promote their recommendation behaviors, and thus improve the vaccine uptake of patients.

In addition, this study showed that compared with public health workers, general practitioners were less willing to get themselves vaccinated against influenza, and less likely to recommend vaccines to children and the elderly. This may partly explain the low uptake level of influenza vaccine among children and elderly in China. However, in routine practice, after receiving the recommendation from public health workers, most patients would consult the general practitioners or specialists for further consultation, and the advice of the general practitioners or specialists would largely determine whether the patient was finally vaccinated [10,30]. Elderly, child and adults with chronic diseases are the priority group for influenza vaccination and their decision to be vaccine might partly depend on advice received from general practitioners [31]. General practitioners may play an important role in improving the influenza vaccination uptake of community residents. Therefore, the currently separated public health and healthcare services in China's primary healthcare facilities hinders the progress in vaccine uptake of seasonal influenza. 
As China moves to expand primary healthcare services as part of its efforts to achieve universal health coverage, adequate training on general practitioners are imperative. The medical education in China put much emphasis on specialization, resulting in detailed but narrowed knowledge structure of medical practitioners [32]. In Table 3, we can find that vaccination status is highly associated with knowledge of the recommended population instead of the type of HCWs in the primary care facilities. The vaccination rate of general practitioners was significantly lower, indicating a large number of general practitioners lacking basic knowledge of influenza vaccination. Therefore, it is necessary to enhance public health education for general practitioners and integrate public health with clinical medicine in practice. Meanwhile, the responsibility of preventing and controlling infectious diseases is jointly shouldered by public health system and medical system, especially during disease outbreaks such as the COVID-19 pandemic [33]. In the long run, improving influenza vaccination coverage among priority groups needs joint efforts from both public health workers and general practitioners. Furthermore, a recent study showed that in the peak season of influenza, the management of respiratory outbreaks like COVID-19 could be facilitated by expanding influenza vaccination coverage [34]. In this sense, encouraging vaccine uptake and recommendation behaviors among HCWs is helpful in the fight against respiratory outbreaks.

The observational study has a few limitations. First, the vaccination behaviors of HCWs were self-reported, causing potential recall bias despite the low possibility for HCWs to misstate their vaccination status. Meanwhile, self-reported influenza coverage has been reported as a good proxy for recorded vaccination [35]. Second, the participants of this study were public health workers and general practitioners who provide services directly to patients, not medical staff in all departments. Even so, the HCWs enrolled in this study had more contacts with patients from 10 provinces across China, which can sufficiently represent Chinese HCWs who are among the priority groups for influenza vaccination. Third, the data collection was cross-sectional, so causality cannot be inferred with certainty.

\section{Conclusions}

In conclusion, this national cohort study suggested that levels of influenza vaccine uptake and recommendation among HCWs are still relatively low in China, especially among general practitioners. Previous history of vaccination and knowledge of and attitudes toward influenza and influenza vaccine were positively associated with vaccine uptake and recommendation behaviors of HCWs, indicating the importance of adequate and coherent training on immunization for both public health workers and general practitioners. These findings hold promise for the refinement of the current influenza vaccination programs in China.

Author Contributions: Conceptualization, L.F. and H.F.; Data curation, H.R., L.F. and H.F.; Formal analysis, X.M., Z.H., S.L., R.J., Z.P. and H.F.; Funding acquisition, H.F.; Investigation, L.F. and H.F.; Methodology, X.M., R.J. and H.Z.; Project administration, L.F.; Supervision, H.F.; Writing-original draft, H.R. and X.L.; Writing-review \& editing, H.R., X.L., Z.H., S.L., R.J., H.Z., Z.P. and L.F. All authors read and approved the final version of the manuscript.

Funding: This work was supported by the National Natural Science Foundation of China (grant number 71774006) and the China Postdoctoral Science Foundation (grant number 2019M650392).

Acknowledgments: We would like to thank all participating healthcare institutions and healthcare workers for their contribution to this study.

Conflicts of Interest: The authors declare no conflict of interest.

\section{References}

1. Dini, G.; Toletone, A.; Sticchi, L.; Orsi, A.; Bragazzi, N.L.; Durando, P. Influenza vaccination in healthcare workers: A comprehensive critical appraisal of the literature. Hum. Vaccin. Immunother. 2018, 14, 772-789. [CrossRef] [PubMed] 
2. Tough, D.F. Influenza's signature move. Nat. Immunol. 2018, 19, 518-520. [CrossRef] [PubMed]

3. Osterholm, M.T.; Kelley, N.S.; Sommer, A.; Belongia, E.A. Efficacy and effectiveness of influenza vaccines: A systematic review and meta-analysis. Lancet. Infect. Dis. 2012, 12, 36-44. [CrossRef]

4. Alsuhaibani, M. Barriers and beliefs among health-care workers regarding seasonal influenza vaccine in Al-Qassim region, Saudi Arabia. Hum. Vaccin. Immunother. 2020, 16, 313-320. [CrossRef] [PubMed]

5. Maltezou, H.C.; Poland, G.A. Immunization of healthcare personnel in Europe: Time to move forward with a common program. Vaccine 2020, 38, 3187-3190. [CrossRef] [PubMed]

6. Technical guidelines for seasonal influenza vaccination in China (2019-2020). Chin. J. Prev. Med. 2020, 54, 21-36. (In Chinese) [CrossRef]

7. Lee, P.H.; Cowling, B.J.; Yang, L. Seasonal influenza vaccination among Chinese health care workers. Am. J. Infect. Control. 2017, 45, 575-578. [CrossRef]

8. Bekkat-Berkani, R.; Romano-Mazzotti, L. Understanding the unique characteristics of seasonal influenza illness to improve vaccine uptake in the US. Vaccine 2018, 36, 7276-7285. [CrossRef]

9. Pereira, M.; Williams, S.; Restrick, L.; Cullinan, P.; Hopkinson, N.S. Healthcare worker influenza vaccination and sickness absence-An ecological study. Clin. Med. (Lond.) 2017, 17, 484-489. [CrossRef]

10. Dominguez, A.; Godoy, P.; Castilla, J.; Maria Mayoral, J.; Soldevila, N.; Torner, N.; Toledo, D.; Astray, J.; Tamames, S.; Garcia-Gutierrez, S.; et al. Knowledge of and attitudes to influenza in unvaccinated primary care physicians and nurses. Hum. Vaccin. Immunother. 2014, 10, 2378-2386. [CrossRef]

11. Zhou, L.; Su, Q.; Xu, Z.; Feng, A.; Jin, H.; Wang, S.; Feng, Z. Seasonal influenza vaccination coverage rate of target groups in selected cities and provinces in China by season (2009/10 to 2011/12). PLoS ONE 2013, 8, e73724. [CrossRef]

12. Yang, J.; Atkins, K.E.; Feng, L.; Pang, M.; Zheng, Y.; Liu, X.; Cowling, B.J.; Yu, H. Seasonal influenza vaccination in China: Landscape of diverse regional reimbursement policy, and budget impact analysis. Vaccine 2016, 34, 5724-5735. [CrossRef] [PubMed]

13. Pelullo, C.P.; Della Polla, G.; Napolitano, F.; Di Giuseppe, G.; Angelillo, I.F. Healthcare Workers' Knowledge, Attitudes, and Practices about Vaccinations: A Cross-Sectional Study in Italy. Vaccines 2020, 8, 148. [CrossRef] [PubMed]

14. Ecarnot, F.; Crepaldi, G.; Juvin, P.; Grabenstein, J.; Del Giudice, G.; Tan, L.; O’Dwyer, S.; Esposito, S.; Bosch, X.; Gavazzi, G.; et al. Pharmacy-based interventions to increase vaccine uptake: Report of a multidisciplinary stakeholders meeting. BMC Public Health 2019, 19, 1698. [CrossRef]

15. Song, Y.; Zhang, T.; Chen, L.; Yi, B.; Hao, X.; Zhou, S.; Zhang, R.; Greene, C. Increasing seasonal influenza vaccination among high risk groups in China: Do community healthcare workers have a role to play? Vaccine 2017, 35, 4060-4063. [CrossRef]

16. Liu, S.; Yuan, H.; Liu, Y.; Du, J.; Zhang, X.; Wang, J.; Che, X.; Xu, E. Attitudes of seasonal influenza vaccination among healthcare worker and general community population after pandemic influenza A/H1N1 in Hangzhou. Hum. Vaccines 2011, 7, 1072-1076. [CrossRef] [PubMed]

17. Chiatti, C.; Barbadoro, P.; Marigliano, A.; Ricciardi, A.; Di Stanislao, F.; Prospero, E. Determinants of influenza vaccination among the adult and older Italian population with chronic obstructive pulmonary disease: A secondary analysis of the multipurpose ISTAT survey on health and health care use. Hum. Vaccines 2011, 7, 1021-1025. [CrossRef] [PubMed]

18. Chen, S.; Chen, Y.; Feng, Z.; Chen, X.; Wang, Z.; Zhu, J.; Jin, J.; Yao, Q.; Xiang, L.; Yao, L.; et al. Barriers of effective health insurance coverage for rural-to-urban migrant workers in China: A systematic review and policy gap analysis. BMC Public Health 2020, 20, 408. [CrossRef]

19. Hou, J.; Michaud, C.; Li, Z.; Dong, Z.; Sun, B.; Zhang, J.; Cao, D.; Wan, X.; Zeng, C.; Wei, B.; et al. Transformation of the education of health professionals in China: Progress and challenges. Lancet 2014, 384, 819-827. [CrossRef]

20. Lu, G.; Zhang, G.; Li, S. Equine influenza vaccine in China: Current status and challenges. Equine. Vet. J. 2018, 50, 544-545. [CrossRef] 
21. Thompson, M.G.; Gaglani, M.J.; Naleway, A.; Ball, S.; Henkle, E.M.; Sokolow, L.Z.; Brennan, B.; Zhou, H.; Foster, L.; Black, C.; et al. The expected emotional benefits of influenza vaccination strongly affect pre-season intentions and subsequent vaccination among healthcare personnel. Vaccine 2012, 30, 3557-3565. [CrossRef] [PubMed]

22. Haridi, H.K.; Salman, K.A.; Basaif, E.A.; Al-Skaibi, D.K. Influenza vaccine uptake, determinants, motivators, and barriers of the vaccine receipt among healthcare workers in a tertiary care hospital in Saudi Arabia. J. Hosp. Infect. 2017, 96, 268-275. [CrossRef] [PubMed]

23. Lorenc, T.; Marshall, D.; Wright, K.; Sutcliffe, K.; Sowden, A. Seasonal influenza vaccination of healthcare workers: Systematic review of qualitative evidence. BMC Health Serv. Res. 2017, 17, 732. [CrossRef] [PubMed]

24. Corace, K.M.; Srigley, J.A.; Hargadon, D.P.; Yu, D.; MacDonald, T.K.; Fabrigar, L.R.; Garber, G.E. Using behavior change frameworks to improve healthcare worker influenza vaccination rates: A systematic review. Vaccine 2016, 34, 3235-3242. [CrossRef] [PubMed]

25. Dorell, C.; Yankey, D.; Strasser, S. Parent-reported reasons for nonreceipt of recommended adolescent vaccinations, national immunization survey: Teen, 2009. Clin. Pediatr. (Phila) 2011, 50, 1116-1124. [CrossRef] [PubMed]

26. Andrew, M.K.; Bowles, S.K.; Pawelec, G.; Haynes, L.; Kuchel, G.A.; McNeil, S.A.; McElhaney, J.E. Influenza Vaccination in Older Adults: Recent Innovations and Practical Applications. Drugs Aging 2019, 36, $29-37$. [CrossRef]

27. Carman, W.F.; Elder, A.G.; Wallace, L.A.; McAulay, K.; Walker, A.; Murray, G.D.; Stott, D.J. Effects of influenza vaccination of health-care workers on mortality of elderly people in long-term care: A randomised controlled trial. Lancet 2000, 35593-35597. [CrossRef]

28. Ballestas, T.; McEvoy, S.P.; Doyle, J. Co-ordinated approach to healthcare worker influenza vaccination in an area health service. J. Hosp. Infect. 2009, 73, 203-209. [CrossRef]

29. Torner, N.; Godoy, P.; Soldevila, N.; Toledo, D.; Rius, C.; Dominguez, A. Primary health care professionals attitudes towards influenza immunzation in Catalonia. Atencion Primaria. 2016, 48, 192-199. [CrossRef]

30. Fabiani, M.; Volpe, E.; Faraone, M.; Bella, A.; Rizzo, C.; Marchetti, S.; Pezzotti, P.; Chini, F. Influenza vaccine uptake in the elderly population: Individual and general practitioner's determinants in Central Italy, Lazio region, 2016-2017 season. Vaccine 2019, 37, 5314-5322. [CrossRef]

31. Desiante, F.; Caputi, G.; Cipriani, R.; Nanula, C.; Aprile, I.; Pesare, A.; Conversano, M. Assessment of coverage and analysis of the determinants of adherence to influenza vaccination in the general practitioners of Taranto. Ann. Ig. 2017, 29, 256-263. [PubMed]

32. Hsieh, C.R.; Tang, C. The multi-tiered medical education system and its influence on the health care market-China's Flexner Report. Hum. Resour. Health 2019, 17, 50. [CrossRef] [PubMed]

33. Pan, A.; Liu, L.; Wang, C.; Guo, H.; Hao, X.; Wang, Q.; Huang, J.; He, N.; Yu, H.; Lin, X.; et al. Association of Public Health Interventions with the Epidemiology of the COVID-19 Outbreak in Wuhan, China. JAMA 2020, 323, 1-9. [CrossRef] [PubMed]

34. Li, Q.; Tang, B.; Bragazzi, N.L.; Xiao, Y.; Wu, J. Modeling the impact of mass influenza vaccination and public health interventions on COVID-19 epidemics with limited detection capability. Math. Biosci. 2020, 325, 108378. [CrossRef] [PubMed]

35. Llupia, A.; Garcia-Basteiro, A.L.; Mena, G.; Rios, J.; Puig, J.; Bayas, J.M.; Trilla, A. Vaccination behaviour influences self-report of influenza vaccination status: A cross-sectional study among health care workers. PLoS ONE 2012, 7, e39496. [CrossRef] [PubMed]

(C) 2020 by the authors. Licensee MDPI, Basel, Switzerland. This article is an open access article distributed under the terms and conditions of the Creative Commons Attribution (CC BY) license (http://creativecommons.org/licenses/by/4.0/). 